\title{
Primary Immunodeficiencies (PID): driving diagnosis for optimal care in Europe
}

\author{
Marta Czerniawska ${ }^{1 *}$, Fred Modell ${ }^{2}$ \\ From 5th European Conference on Rare Diseases (ECRD 2010) \\ Krakow, Poland. 13-15 May 2010
}

Primary Immunodeficiencies (PID) are defects of the immune system that cause increased susceptibility to infections that are chronic, persistent, recurring, debilitating, and often fatal. There are more than 150 PID diseases, which affect more than 10 million people worldwide.

PID are often manageable, if properly evaluated and treated. However, awareness of these diseases is low amongst both primary care physicians and the general public. As a result, many patients are left undiagnosed. Delayed diagnosis and insufficient treatment leads to increased morbidity, mortality, and inflated medical costs, in addition to a life of chronic illness and suffering.

The Jeffrey Modell Foundation (JMF) was established in 1987 in memory of our son, Jeffrey, who died at the age of 15 after struggling with a PID. JMF's mission is to assure early and precise diagnosis, meaningful treatments, and ultimately, cures of the ever increasing known PID diseases.

JMF initiated a Physician Education and Public Awareness Campaign to create greater awareness and encourage the earliest possible diagnose and precise treatment. This global campaign has had extraordinary results. Expert physicians from the Jeffrey Modell Centres Network of 72 Diagnostic and Research Centres and more than 196 Referral Centres worldwide have reported annual increases of more than $25 \%$ in the numbers of patients referred, patients followed, and patients identified with a specific PID. To date, more than 414 physicians from 176 teaching hospitals in 51 countries participate in the Jeffrey Modell Centres Network.

\footnotetext{
*Correspondence: marta.czerniawska@interel.eu

'Jeffrey Modell Foundation, c/o Interel European Affairs, Rue du Luxembourg 22-24, 1000 Brussels, Belgium

Full list of author information is available at the end of the article
}

Nearly half of the Jeffrey Modell Diagnostic, Research and Referral Centres are located in Western, Central, and Eastern Europe. This European Network of Diagnostic Centres promotes improvements in the standard of care for patients with PID by fostering collaboration, measuring outcomes, sharing data, and serving the patients, families and caregivers of those affected by PID, and serves as a successful model for other diseases.

\section{Author details}

${ }^{1}$ Jeffrey Modell Foundation, c/o Interel European Affairs, Rue du Luxembourg 22-24, 1000 Brussels, Belgium. ${ }^{2}$ Jeffrey Modell Foundation, 747 Third Avenue, New York 10017, USA.

Published: 19 October 2010

doi:10.1186/1750-1172-5-S1-P10

Cite this article as: Czerniawska and Modell: Primary Immunodeficiencies (PID): driving diagnosis for optimal care in Europe. Orphanet Journal of Rare Diseases 2010 5(Suppl 1):P10.

\author{
Submit your next manuscript to BioMed Central \\ and take full advantage of: \\ - Convenient online submission \\ - Thorough peer review \\ - No space constraints or color figure charges \\ - Immediate publication on acceptance \\ - Inclusion in PubMed, CAS, Scopus and Google Scholar \\ - Research which is freely available for redistribution \\ Submit your manuscript at \\ www.biomedcentral.com/submit
}

